Annals of Pure and Applied Mathematics

Vol. 16, No. 2, 2018, 419-428

ISSN: 2279-087X (P), 2279-0888(online)

Published on 14 March 2018

www.researchmathsci.org

DOI: http://dx.doi.org/10.22457/apam.v16n2a19

Annals of

Pure and Applied

Mathematics

\title{
MHD Free Convective Flow Through Porous Medium Past an Infinite Vertical Plate
}

\author{
K.Subbanna ${ }^{1}$, S. Gouse Mohiddin ${ }^{2}$ and R.Bhuvana Vijaya ${ }^{3}$ \\ 1,2 Department of Mathematics, Madanapalle Institute of Technology \& Science \\ Madanapalle -517325, A.P, India. E-mail: subbu07mtech@gmail.com \\ ${ }^{3}$ Department of Mathematics, JNTUA College of Engineering \\ Anantpur, A.P.,India.
}

Received 21 February 2018; accepted 12 March 2018

\begin{abstract}
In this paper, the unsteady MHD free convective flow through porous medium over an infinite vertical plate under the influence of uniform transverse magnetic field of strength $\mathrm{H}_{0}$ has been discussed. The flow is induced by a general time dependent movement of vertical plate. The exact solutions for the velocity, temperature and concentration are obtained making use of Laplace transform technique. The effect of various governing flow parameters on the velocity, temperature and concentration are analyzed, and numerical solutions for the skin friction, Nusselt number and Sherwood number are also obtained and discussed.
\end{abstract}

Keywords: Heat and mass transfer, infinite vertical flat plate, Laplace transform technique, MHD flows, porous medium

AMS Mathematics Subject Classification (2010): 80Axx, 80Mxx 76Wxx

\section{Introduction}

MHD free convection fluid flows frequently occur in natural world. Flow through porous medium is a great interest and attract towards the applications in the fields of science and technology namely in the area of agriculture engineering to know about the ground water resources, in fuel technology to study the moment of natural gas, oil, and water through the oil reservoirs. Studied the effects of chemical reaction, Studied radiation effects on MHD flow through a porous medium with variable temperature or variable mass diffusion. Kesavaiah et al. [1] Many authors [2] discussed MHD free convection heat and mass transfer flow embedded in porous medium with heat source and suction. Reddy et al. [3] discussed radiation absorption, chemical reaction and magnetic field effects on the free convection and mass transfer flow through porous medium. Raju et al. [4] studied unsteady MHD free convection and chemically reactive flow past an infinite vertical porous plate. Umamaheswar et al. [5] investigated heat and mass transfer in MHD flow of a viscous fluid past a vertical plate under oscillatory suction velocity. Reddy et al. [6] had presented thermal radiation and chemical reaction effects on MHD mixed convective boundary layer slip flow in a porous medium with heat source and Ohmic heating. Rout et al. [7] discussed effect of radiation and chemical reaction on free convective MHD 
K.Subbanna, S. Gouse Mohiddin and R.Bhuvana Vijaya

flow through a porous medium with double diffusion. Effects of chemical reaction and radiation absorption on MHD flow of dusty visco-elastic fluid were considered by Prakash et al. [8] investigated combined effects of heat absorption and MHD on convective Rivlin-Ericksenflow past a semi-infinite vertical porous plate. Raghunath et al. [9] Studied MHD natural convective rotating flow of a viscous, electrically conducting and incompressible fluid over an impulsively moving vertical plate embedded in porous medium, Wahiduzzaman et al. [10] Studied Unsteady MHD-Free Convection Flow Past from a Rotating Vertical Plate with the Influence of Hall and Ion-slip Current.Md. Mizanur Rahman et al. [11] Studied Numerical Simulation on MHD Free Convection Mass and Heat Transfer Fluid Flow over a Vertical Porous Plate in a Rotating System with Induced Magnetic Field.

Keeping the above mentioned facts, in this paper, the unsteady MHD free convective flow through porous medium over an infinite vertical plate under the influence of uniform transverse magnetic field of strength $\mathrm{H}_{0}$ has been discussed.

\section{Mathematical formulation and solution of the problem}

We consider the unsteady MHD free convection flow of an electrically conducting viscous incompressible fluid through porous medium over an infinite vertical plate subjected to a uniform transverse magnetic field of strength $\mathrm{B}_{0}$ normal to plate. The physical configuration of the problem is presented in the Fig. 1.

We choose a Cartesian co-ordinate system $O(x, y, z)$ such that $\mathrm{x}, \mathrm{y}$ axes respectively are in the vertical upward and perpendicular directions on the plane. i.e., the $\mathrm{x}$-axis is along the plate in the upward direction, $\mathrm{y}$-axis normal to it and $\mathrm{z}$-axis normal to the xy-plane. The fluid is permeated by a uniform transverse magnetic field of strength $\mathrm{B}_{0}$ applied to along the y-axis. For time $t<0$, the stationary plate and the fluid are at the constant temperature $T_{\infty}$ and species concentration $C_{\infty}$

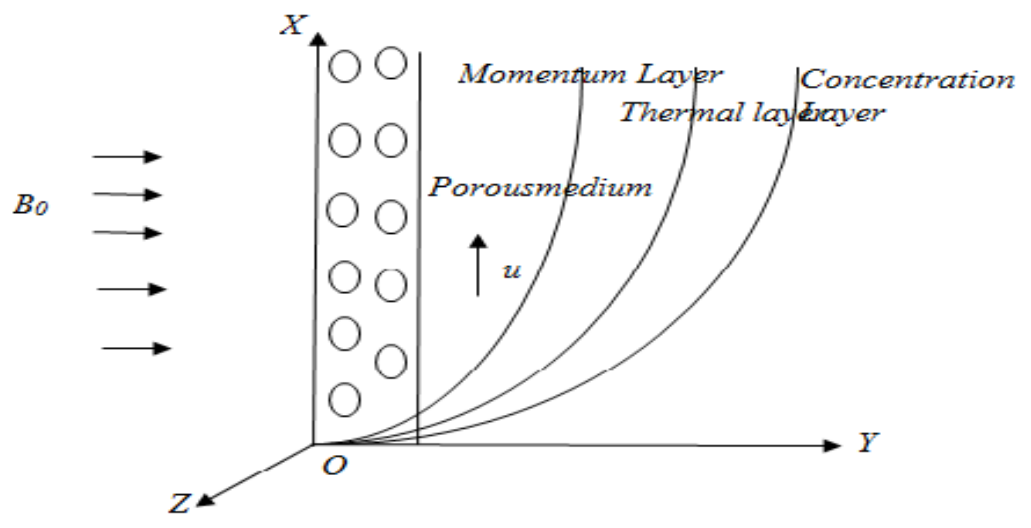

Figure 1: Physical configuration of the problem

At time $t=0$, the plate begins to move with a time dependent velocity $u_{0} f(t)$ in its own plane along the $\mathrm{x}$-axis and the temperature of the plate is raised or lowered to $T_{\infty}+\left(T_{w}-T_{\infty}\right) \frac{t}{t_{0}}$, when $t<t_{0}$ and thereafter for $t>t_{0}$ it is maintained at a uniform 
MHD Free Convective Flow Through Porous Medium Past an Infinite Vertical Plate temperature $T_{w}$. Also for time ${ }^{t>0}$ species concentration is raised to $C_{\infty}$. Since the plate is of infinite extent in $\mathrm{x}$ and $\mathrm{z}$ direction, and is electrically non-conducting, all the physical quantities except pressure, are functions of y and $t$ only. Magnetic Reynolds number is so small, and hence the induced magnetic field produced by the fluid motion is negligible in comparison to the applied magnetic field $B=\left(0, B_{0}, 0\right)$, the governing equations are given by,

$$
\begin{aligned}
& \frac{\partial u}{\partial t}=v \frac{\partial^{2} u}{\partial y^{2}}-\frac{\sigma B_{0}}{\rho} u-\frac{v}{K_{1}} u+g \beta\left(T-T_{\infty}\right)+g \beta^{*}\left(C-C_{\infty}\right) \\
& \frac{\partial T}{\partial t}=\frac{k}{\rho C_{p}} \frac{\partial^{2} T}{\partial y^{2}}-\frac{Q_{0}}{\rho C_{p}}\left(T-T_{\infty}\right) \\
& \frac{\partial C}{\partial t}=D \frac{\partial^{2} C}{\partial z^{2}}
\end{aligned}
$$

Assuming no-slip between the plate and fluid, the initial and boundary conditions are,

$u=0, T=T_{\infty}, C=C_{\infty}$, for $t \leq 0$ and $y \geq 0$

$u=u_{0} f(t), C=C_{w}$, at $t>0$ and $y=0$

$T=T_{\infty}+\left(T_{w}-T_{\infty}\right) \frac{t}{t_{0}}$ at $y=0$ for $0<t \leq t_{0}$

$T=T_{\infty} \quad$ at $y=0$ for $t>t_{0}$

$u=0, T \rightarrow T_{\infty}, C \rightarrow C_{\infty}$, as $y \rightarrow \infty$ for $t>0$

Introducing the following non-dimensional quantities:

$$
y^{*}=\frac{y}{u_{0} t_{0}}, u^{*}=\frac{u}{t_{0}}, t^{*}=\frac{t}{t_{0}}, T^{*}=\frac{T-T_{\infty}}{T_{w}-T_{\infty}}, C^{*}=\frac{C-C_{\infty}}{C_{w}-C_{\infty}}
$$

Using non-dimensional quantities (dropping asterisks), the governing equations (1), (2) and (3) can be written as

$$
\begin{aligned}
& \frac{\partial u}{\partial t}=\frac{\partial^{2} u}{\partial y^{2}}-\left(M^{2}+\frac{1}{K}\right) u+G_{r} T+G_{m} C \\
& \frac{\partial T}{\partial t}=\frac{1}{\operatorname{Pr}} \frac{\partial^{2} T}{\partial y^{2}}-\varphi T \\
& \frac{\partial C}{\partial t}=\frac{1}{S c} \frac{\partial^{2} C}{\partial y^{2}}
\end{aligned}
$$

where,

$M^{2}=\frac{\sigma B_{0}^{2} v}{\rho u_{0}^{2}}$ is the Hartmann number (Magnetic field parameter), $K=\frac{K_{1} u_{0}^{2}}{v^{2}}$ is the Porosity parameter, $G_{r}=\frac{g \beta v\left(T_{w}-T_{\infty}\right)}{u_{0}^{3}}$ is the thermal Grashof 
K.Subbanna, S. Gouse Mohiddin and R.Bhuvana Vijaya

number, $G_{m}=\frac{g \beta^{*} v\left(C_{w}-C_{\infty}\right)}{u_{0}^{3}}$ is the mass Grashof number, $\operatorname{Pr}=\frac{\rho v C_{p}}{k}$ is Prandtl parameter, $\varphi=\frac{Q_{0} v}{\rho C_{p} u_{0}^{2}}$ is the Heat absorption parameter and $S c=\frac{\nu}{D}$ is the Schmidt number.

The corresponding non-dimensional boundary conditions

$u=0, T=0, C=0$, for $t \leq 0$ and $y \geq 0$

$u=f(t), C=1$, for $t>0$ and $y=0$

$T=t$ for $0<t \leq 1$ at $y=0$

$T=1$ for $t>1$ at $y=0$

$u=0, T=0, C=0$, for $t>0$ as $y \rightarrow \infty$

\section{Results and discussion}

The velocity, temperature and species concentration profiles are given in Figures (2-17), (18-21) and (22-23) respectively when $\omega=\pi / 2$ for both ramped temperature and isothermal plates. The numerical values of the skin friction, Nusselt number and Sherwood number are presented in Tables (1-2) again for both ramped temperature and isothermal plates. The computational results carried out using Mathematica Software.

Figures (2-3 and 10-15) shown that for both ramped temperature and isothermal plates, the fluid velocity decreases with an increase in $\mathrm{M}, \varphi, \mathrm{Sc}$ or $\operatorname{Pr}$, whereas it increases with an increase in K, Gr or Gm (Figs 4-9). The application of a transverse magnetic field on an electrically conducting fluid gives rise to a resistive-type of force called the Lorentz force.

Figures (16-17) shows that for both ramped temperature and isothermal plates, the fluid velocity increases with an increase in $t$ throughout the fluid region. The fluid velocity in the case of a flow past an isothermal plate is higher than that of a flow past a ramped temperature plate.

The computational results for the Concentration profiles for variation in $\mathrm{t}$, and $\mathrm{Sc}$ are shown in Fig. (22-23). In the presence of porous matrix the concentration boundary layer became thinner and thinner as Schmidt number increases. It is observed that the concentration profile is asymptotic in nature. Concentration increases with time whereas it reduces with Schmidt number increases throughout the fluid region.

The numerical computation of skin friction coefficient, Nusselt number and Sherwood number is obtained and presented in Table (1-2). 
MHD Free Convective Flow Through Porous Medium Past an Infinite Vertical Plate

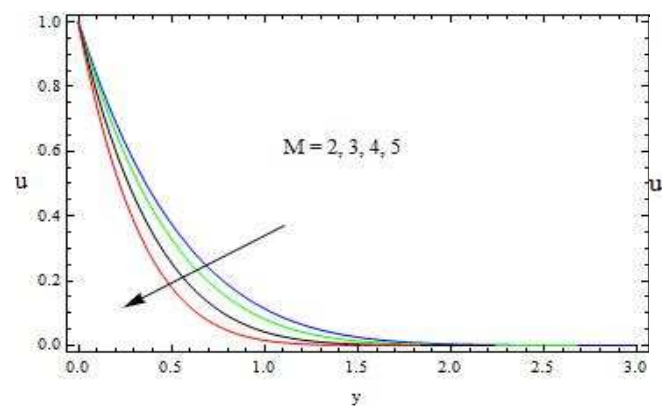

Figure 2: The velocity profile against $\mathrm{M}$ for ramped temperature with $\mathrm{K}=1, \mathrm{Pr}=0.71, \mathrm{Gr}=2, \mathrm{Gm}=2$,

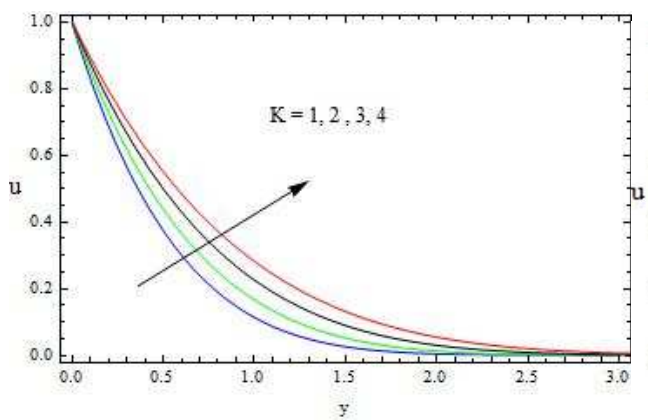

Figure 4: The velocity profile against $\mathrm{K}$ for ramped temperature with $\mathrm{M}=2$, $\operatorname{Pr}=0.71, \mathrm{Gr}=2, \mathrm{Gm}=2, \phi=1, \mathrm{Sc}=0.22, \mathrm{t}=0.2$

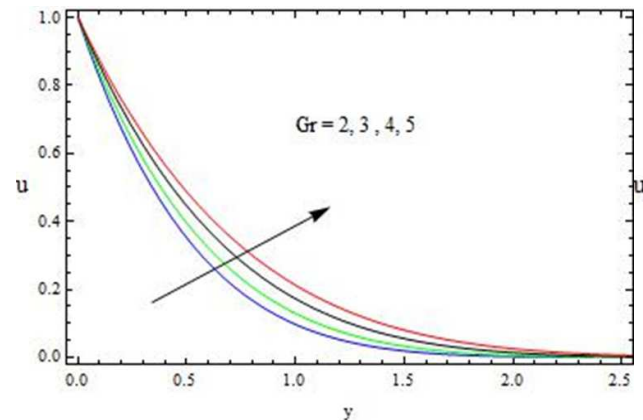

Figure 6: The velocity profile against $\mathrm{Gr}$ for ramped temperature with $\mathrm{M}=2, \operatorname{Pr}=0.71$, $\mathrm{K}=1, \mathrm{Gm}=2, \phi=1, \mathrm{Sc}=0.22, \mathrm{t}=0.2$

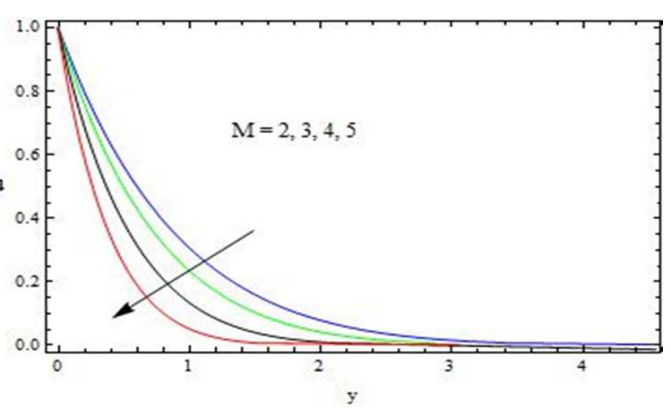

Figure 3: The velocity profile against $\mathbf{M}$ for isothermal plate with $\mathrm{K}=1, \operatorname{Pr}=0.71$, $\mathrm{Gr}=2, \mathrm{Gm}=2, \phi=1, \mathrm{Sc}=0.22, \mathrm{t}=0.2$

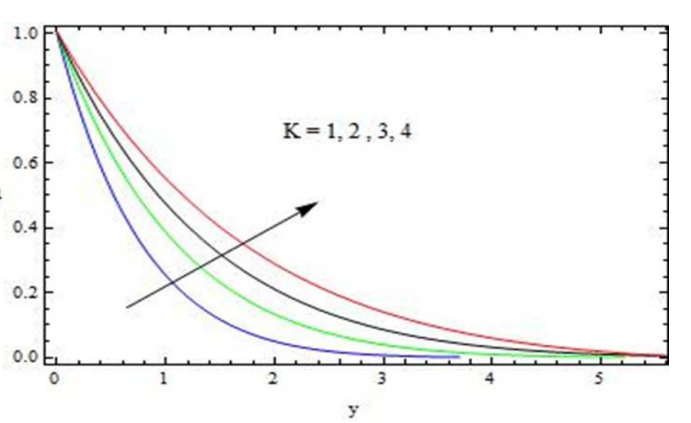

Figure 5: Isothermal plate with $\mathrm{M}=2$, $\operatorname{Pr}=0.71, \mathrm{Gr}=2, \mathrm{Gm}=2, \phi=1, \mathrm{Sc}=0.22, \mathrm{t}=0.2$

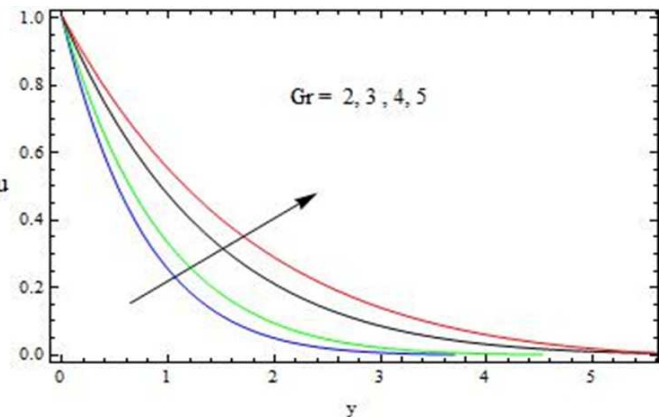

Figure 7: The velocity profile against $\mathrm{Gr}$ for isothermal plate with $\mathrm{M}=2, \mathrm{Pr}=0.71$, $\mathrm{K}=1, \mathrm{Gm}=2, \phi=1, \mathrm{Sc}=0.22, \mathrm{t}=0.2$ 
K.Subbanna, S. Gouse Mohiddin and R.Bhuvana Vijaya

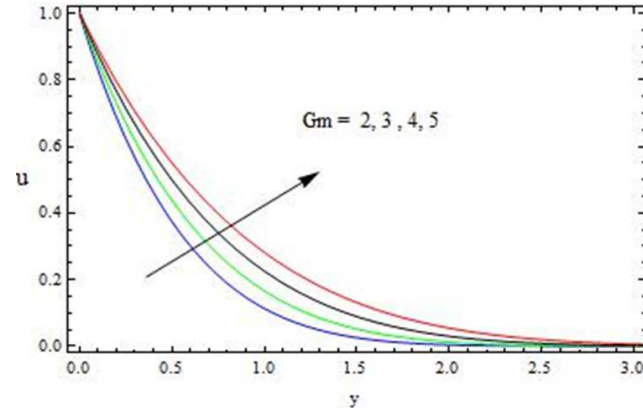

Figure 8: The velocity profile against $\mathrm{Gm}$ for ramped temperature with $\mathrm{M}=2, \mathrm{Pr}=0.71$, $\mathrm{K}=1, \mathrm{Gr}=2, \phi=1, \mathrm{Sc}=0.22, \mathrm{t}=0.2$

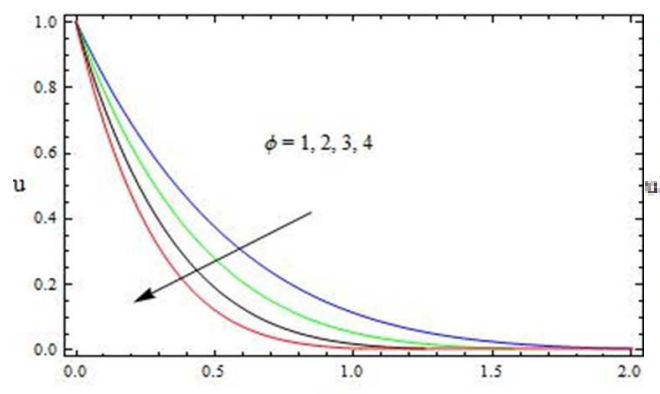

Figure 10: The velocity profile against $\phi$ for ramped temperature with $\mathrm{M}=2, \mathrm{Pr}=0.71$, $\mathrm{K}=1, \mathrm{Gr}=2, \mathrm{Gm}=2, \mathrm{Sc}=0.22, \mathrm{t}=0.2$

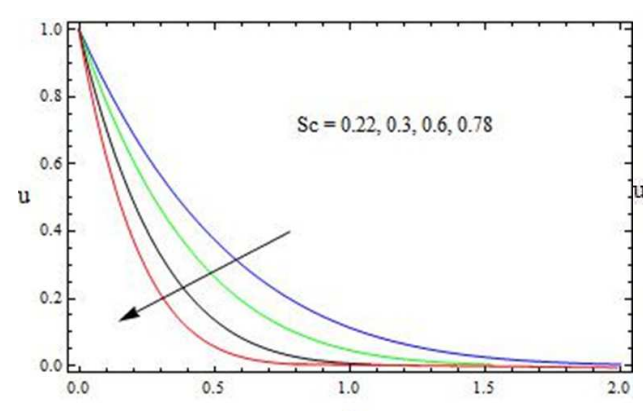

Figure 12: The velocity profile against $\mathrm{Sc}$ for ramped temperature with $\mathrm{M}=2, \mathrm{Pr}=0.71$, $\mathrm{K}=1, \mathrm{Gr}=2, \mathrm{Gm}=2, \mathrm{t}=0.2$

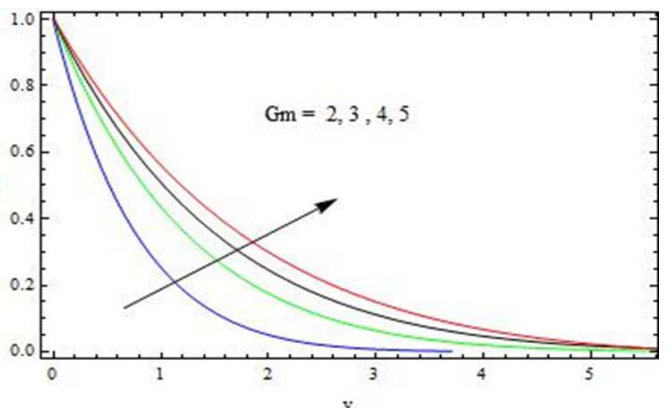

Figure 9: The velocity profile against $\mathrm{Gm}$ for isothermal plate with $\mathrm{M}=2, \operatorname{Pr}=0.71$, $\mathrm{K}=1, \mathrm{Gr}=2, \phi=1, \mathrm{Sc}=0.22, \mathrm{t}=0.2$

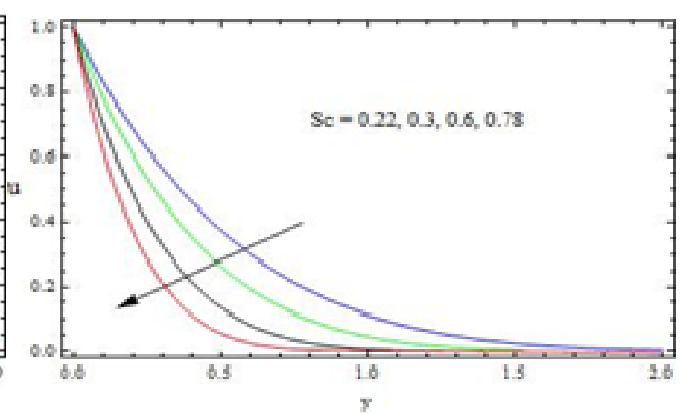

Figure 11: The velocity profile against for isothermal plate with $\mathrm{M}=2, \operatorname{Pr}=0.71$, $\mathrm{K}=1, \mathrm{Gr}=2, \mathrm{Gm}=2, \mathrm{Sc}=0.22, \mathrm{t}=0.2$

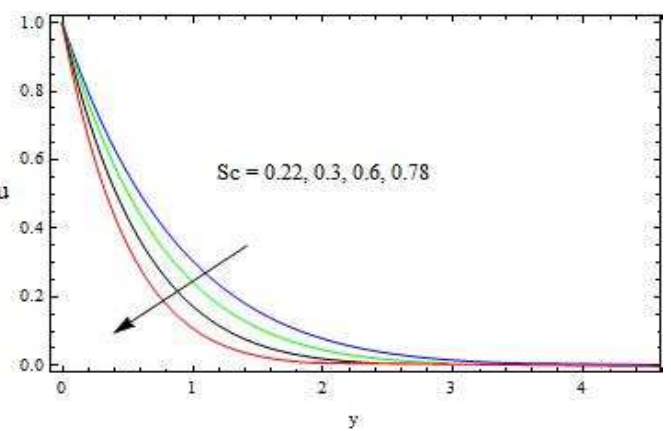

Figure 13: The velocity profile against $\mathrm{Sc}$ for isothermal plate with $\mathrm{M}=2, \operatorname{Pr}=0.71$, $\mathrm{K}=1, \mathrm{Gr}=2, \mathrm{Gm}=2, \phi=1, \mathrm{t}=0.2$ 
MHD Free Convective Flow Through Porous Medium Past an Infinite Vertical Plate
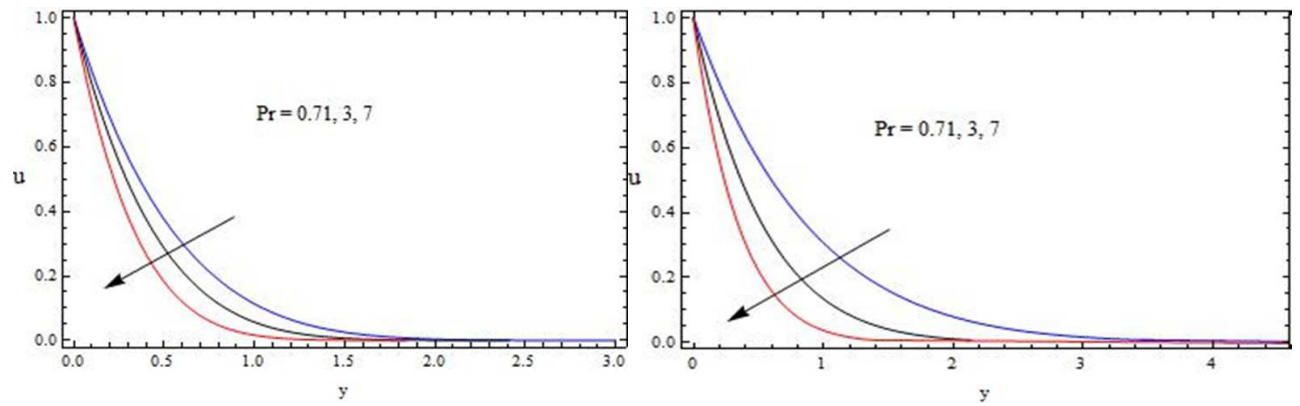

Figure 14: The velocity profile against $\operatorname{Pr}$

Figure 15: The velocity profile against $\mathrm{Pr}$ for ramped temperature with $\mathrm{M}=2, \mathrm{Sc}=0.22$, $\mathrm{K}=1, \mathrm{Gr}=2, \mathrm{Gm}=2, \phi=1, \mathrm{t}=0.2$ for isothermal plate with $\mathrm{M}=2, \mathrm{Sc}=0.22$, $\mathrm{K}=1, \mathrm{Gr}=2, \mathrm{Gm}=2, \phi=1, \mathrm{t}=0.2$
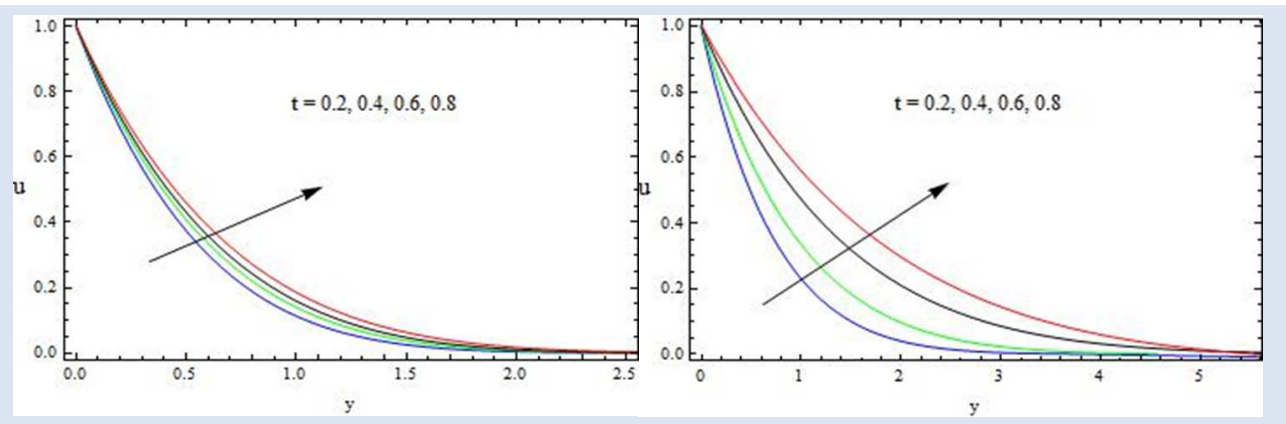

Figure 16: The velocity profile against $t$ for ramped temperature with $\mathrm{M}=2, \mathrm{Sc}=0.22$, $\mathrm{K}=1, \mathrm{Gr}=2, \mathrm{Gm}=2, \mathrm{Pr}=0.71$

Figure 17: The velocity profile against $t$ for isothermal plate with $\mathrm{M}=2, \mathrm{Sc}=0.22$, $\mathrm{K}=1, \mathrm{Gr}=2, \mathrm{Gm}=2, \phi=1, \mathrm{Pr}=0.71$
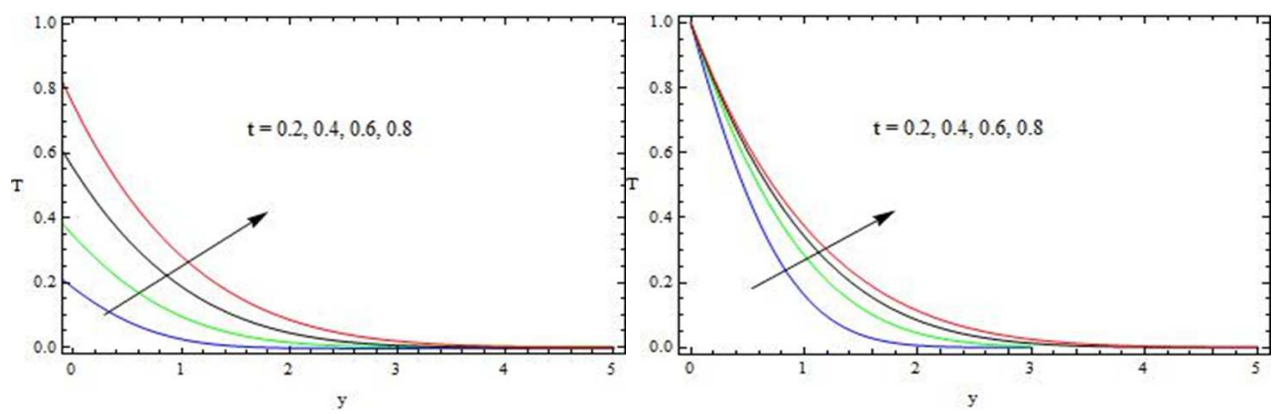

Figure 18: The temperature profile against $t$ Figure 19: The temperature profile against for ramped temperature with $\phi=1, \operatorname{Pr}=0.71$

t for isothermal plate with $\phi=1, \operatorname{Pr}=0.71$ 
K.Subbanna, S. Gouse Mohiddin and R.Bhuvana Vijaya

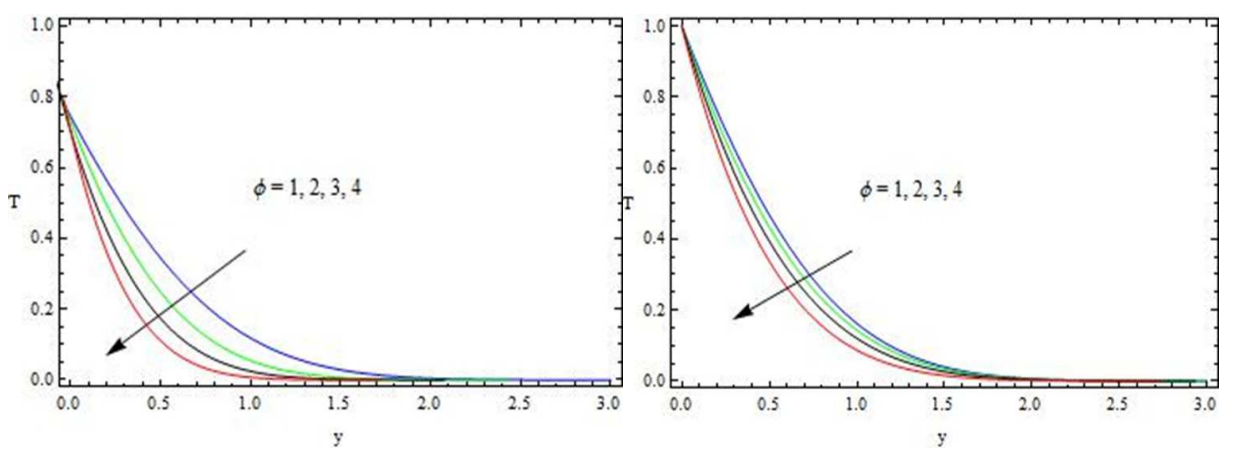

Figure 20: The temperature profile against Figure 21: The temperature profile against $\phi$ for ramped temperature with $\mathrm{t}=0.8$, $\phi$ for isothermal plate with $\mathrm{t}=0.2, \operatorname{Pr}=0.71$

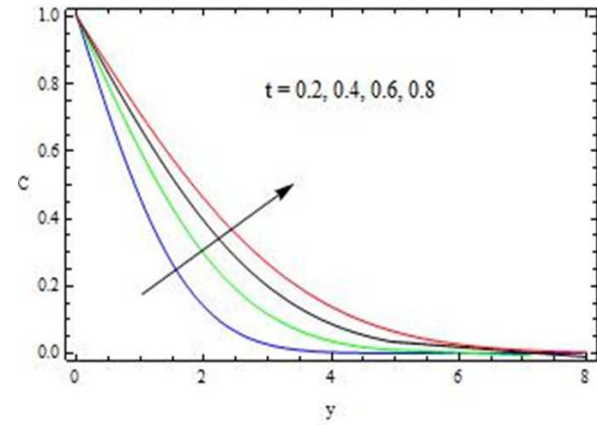

Figure 22: The concentration profile against $\phi$ with $\mathrm{Sc}=0.22$

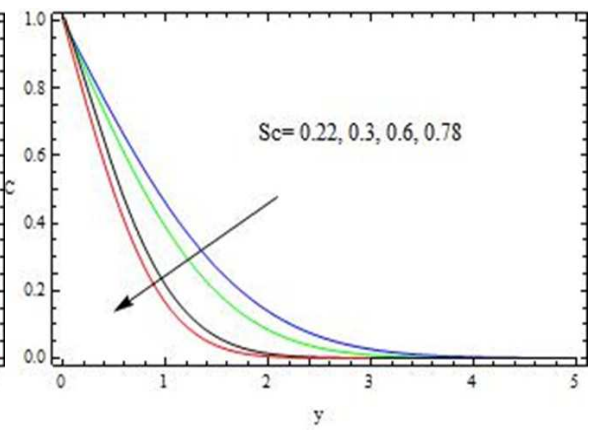

Figure 23: The Concentration profile against Sc with $\phi$

Table 1: Skin friction

\begin{tabular}{|c|c|c|c|c|c|c|c|c|c|}
\hline $\mathrm{M}$ & $\mathrm{K}$ & $\varphi$ & $\mathrm{Pr}$ & $\mathrm{Gr}$ & $\mathrm{Gm}$ & $\mathrm{Sc}$ & $\mathrm{t}$ & $\tau_{11}$ & $\tau_{12}$ \\
\hline 2 & 1 & 1 & 0.71 & 2 & 2 & 0.22 & 0.2 & -0.807552 & -0.025256 \\
\hline 3 & 1 & 1 & 0.71 & 2 & 2 & 0.22 & 0.2 & -0.725452 & -0.014855 \\
\hline 4 & 1 & 1 & 0.71 & 2 & 2 & 0.22 & 0.2 & -0.624989 & -0.000455 \\
\hline 2 & 2 & 1 & 0.71 & 2 & 2 & 0.22 & 0.2 & -0.747748 & -0.014452 \\
\hline 2 & 3 & 1 & 0.71 & 2 & 2 & 0.22 & 0.2 & -0.602784 & -0.009996 \\
\hline 2 & 1 & 2 & 0.71 & 2 & 2 & 0.22 & 0.2 & -1.225632 & -0.035625 \\
\hline 2 & 1 & 3 & 0.71 & 2 & 2 & 0.22 & 0.2 & -2.870014 & -0.041475 \\
\hline 2 & 1 & 1 & 3 & 2 & 2 & 0.22 & 0.2 & -0.902747 & -0.074452 \\
\hline 2 & 1 & 1 & 7 & 2 & 2 & 0.22 & 0.2 & -1.255440 & -0.14445 \\
\hline 2 & 1 & 1 & 0.71 & 3 & 2 & 0.22 & 0.2 & -1.255522 & -0.125210 \\
\hline 2 & 1 & 1 & 0.71 & 4 & 2 & 0.22 & 0.2 & -1.355455 & -0.859963 \\
\hline 2 & 1 & 1 & 0.71 & 2 & 3 & 0.22 & 0.2 & -2.854748 & -0.998546 \\
\hline 2 & 1 & 1 & 0.71 & 2 & 4 & 0.22 & 0.2 & -3.558966 & -1.845510 \\
\hline 2 & 1 & 1 & 0.71 & 2 & 2 & 0.6 & 0.2 & -0.690748 & -0.009633 \\
\hline
\end{tabular}


MHD Free Convective Flow Through Porous Medium Past an Infinite Vertical Plate

Table 2: Nusselt number

\begin{tabular}{|l|l|l|l|l|}
\hline $\mathbf{t}$ & $\phi$ & $\mathbf{P r}$ & $\begin{array}{l}\text { At Ramped } \\
\text { temperature } \\
\text { (Nu) }\end{array}$ & $\begin{array}{l}\text { At } \\
\text { isothermal } \\
\text { plate }(\mathbf{N u})\end{array}$ \\
\hline $\mathbf{0 . 2}$ & $\mathbf{1}$ & $\mathbf{0 . 7 1}$ & 0.857396 & -0.658155 \\
\hline $\mathbf{0 . 4}$ & $\mathbf{1}$ & $\mathbf{0 . 7 1}$ & 1.243430 & -0.978467 \\
\hline $\mathbf{0 . 6}$ & $\mathbf{1}$ & $\mathbf{0 . 7 1}$ & 1.589440 & -1.283285 \\
\hline $\mathbf{0 . 2}$ & $\mathbf{2}$ & $\mathbf{0 . 7 1}$ & 1.253952 & -1.066595 \\
\hline $\mathbf{0 . 2}$ & $\mathbf{3}$ & $\mathbf{0 . 7 1}$ & 1.624698 & -1.447939 \\
\hline $\mathbf{0 . 2}$ & $\mathbf{1}$ & $\mathbf{3}$ & 1.762434 & -1.352882 \\
\hline $\mathbf{0 . 2}$ & $\mathbf{1}$ & $\mathbf{7}$ & 2.692163 & -2.066561 \\
\hline
\end{tabular}

\section{Conclusion}

The conclusions are made as follows:

1. Heat absorption reduces the fluid temperature, whereas thermal diffusion and time have the opposite effect,

2. Heat absorption and the magnetic field tend to retard the fluid flow, whereas thermal diffusion, mass diffusion, thermal buoyancy force and mass buoyancy force and porosity have the opposite effect.

3. The mass diffusion rate and time tend to increase species concentration,

4. Heat absorption and the magnetic field tend to increase the shear stress at the plate, whereas thermal diffusion, thermal buoyancy force and mass buoyancy force have the reverse effect,

5. Heat absorption and time tend to increase the rate of heat transfer at the plate, whereas thermal diffusion has the reverse effect, and mass diffusivity and time tend to reduce the rate of mass transfer at the plate.

Acknowledgement. We would like to show our gratitude to the Supervisor and CoSupervisor for sharing their pearls of wisdom with us during the course of this research, and we thank "anonymous" reviewers for their so-called insights. We are also immensely grateful for their comments on an earlier version of the manuscript, although any errors are our own and should not tarnish the reputations of these esteemed persons.

\section{REFERENCES}

1. C.D.Kesavaiah and P.V.Satyanarayana, Radiation and mass transfer effects on moving vertical plate with variable temperature and viscous dissipation, International Journal of Mathematical Archive, 3 (2012) 3028-3035.

2. P.V.Satyanarayana, MHD free convective heat and mass transfer past a vertical porouse plate with variable temperature, International Journal of Applied Mathematics and Mechanics, 9 (2013) 66-69.

3. S.Venkata, R.Reddy and G.V.Reddy, Effect of chemical reaction and radiation absorption on unsteady MHD double diffusive convective flow of viscous fluid past a semi-infinite porous plate, International Journal of Advanced Engineering Technology, IV (2013) 37-44.

4. M.C.Raju, S.V.K.Varma and R.R.K.Rao, Unsteady MHD free convection and 
K.Subbanna, S. Gouse Mohiddin and R.Bhuvana Vijaya

chemically reactive flow past an infinite vertical porous plate, Journal of Future Engineering and Technology, 8 (2013) 35-40.

5. M.Umamaheswar, S.V.K.Varma and M.C.Raju, Unsteady MHD free convective visco-elastic fluid flow bounded by an infinite inclined porous plate in the presence of heat source, viscous dissipation and ohmic heating, International Journal of Advanced Science and Technology, 61 (2013) 39-52.

http://dx.doi.org/10.14257/ijast.2013.61.05

6. M.G.Reddy, Thermal radiation and chemical reaction effects on MHD mixed convective boundary layer slip flow in a porous medium with heat source and ohmic heating, The European Physical Journal Plus, 129 (2014) 41.

http://dx.doi.org/10.1140/epjp/i2014-14041-3.

7. B.R.Rout, Effect of radiation and chemical reaction on natural convective MHD flow through a porous medium with double diffusion, Journal of Engineering Thermophysic, 23 (2014) 53-65. http://dx.doi.org/10.1134/S181023281401007X.

8. J.Prakash, Effects of chemical reaction and radiation absorption on MHD flow of dusty viscoelastic fluid, Applications and Applied Mathematics, 9 (2014) 141-156.

9. K.Raghunath, R.Siva Prasad and G.S.S.Raju, Hall effects on MHD convective rotating flow of through a porous mediumpast infinite vertical plate, Annals of Pure and Applied Mathematics, 16(2) (2018) 353-263.

10. M.Wahiduzzaman, G.C.Mazumder, Unsteady MHD-free convection flow past from a rotating vertical plate with the influence of hall and ion-slip current, Annals of Pure and Applied Mathematics, 9(1) (2015) 91-106.

11. Md. Mizanur Rahman, Md. Abdul Hye, Numerical simulation on MHD free convection mass and heat transfer fluid flow over a vertical porous plate in a rotating system with induced magnetic field, Annals of Pure and Applied Mathematics, 7(2) (2014) 35-44. 